\title{
A study on the effects of exercise motivation of the elderly people on euphoria
}

\author{
Ah-Ra Oh', Eun-Surk Yi** \\ 'Department of Physical Education, Busan National University of Education, Busan, Korea \\ ${ }^{2}$ Department of Exercise Rehabilitation \& Welfare, College of Health Science, Gachon University, Incheon, Korea
}

The present study aimed to empirically determine the relationship between the degree of exercise participation by the elderly people and their euphoria. The analysis results are as follows. First, the difference between the elderly people's participation in the exercises and the euphoria that they have experienced showed that in all low variables of euphoria, the group who participated in the exercises showed a higher level of euphoria than the group who did not participate in the exercises. Second, the analysis of the effects of the elderly people's motivations for exercise participation on euphoria showed that there was a significant relation between the two. Furthermore, the following suggestions were made for areas that the current study did not cover, as well as for the follow-up studies. The follow-up studies would need an in-depth multiangled analysis of various fun factors in order to encourage the elderly people to participate in the exercises by conducting interviews and observation studies with the study participants.

Keywords: Euphoria, Elderly people, Exercise motivation

\section{INTRODUCTION}

With the advent of the aging society and century-old era, there has been an increase in the importance of a government-led promotion of exercise and physical activities of the elderly people as an alternative to the elderly welfare and health care expenditure savings in South Korea. As a result, there are various government policies that focus on elderly welfare. Relevant government agencies are also exercising their own policies for the improvement of the elderly welfare and the quality of their life through the development and promotion of physical activity programs for the elderly, expansion of the support for physical activities, and professionals who specialize in the elderly health and physical activity programs. In particular, the government has established the First Basic Plan (Draft) in the Low Birth Rate and Aging Society (2006-2010) and 'SAEROMAGI PLAN 2015' (2011-2015), which is the Second Basic Plan in the Basic Act on Low Birth Rate and Aging Society, thereby striving to the activation of physical exercise projects for the promotion of elderly health, the infra- structure improvement on physical exercise, the development and distribution of the elderly health and physical exercise programs, the promotion of physical education toward a lifelong health promotion, and the placement of specialists on elderly exercise maintenance (Ministry of Health and Welfare, 2016).

In addition, the government has developed elderly leisure programs for the 'expansion of the infrastructure for the leisure culture of the elderly people,' distributed them to senior welfare centers and community centers, and dispatched professional trainers, thereby showing that in an aging society, the elderly people's participation in the exercise and physical programs is a key factor in improving their quality of life. Since their activity is limited due to physical aging, these programs are centered on elderly leisure and welfare facilities to provide central facilities for the elderly people that offer easy access and promote their participation in physical activities as well as leisure activities. Despite such promotional activities of the government for the elderly people's participation in the exercises, the Survey on the Elderly People conducted by the Ministry of Health and Welfare in 2014 showed
${ }^{\star}$ Corresponding author: Eun-Surk Yi (D) https://orcid.org/0000-0002-9370-5231 Department of Exercise Rehabilitation \& Welfare, College of Health Science, Gachon University, 191 Hambangmoe-ro, Yeonsu-gu, Incheon 21936, Korea Tel: +82-32-820-4442, Fax: +82-32-820-4442, E-mail: Yies@gachon.ac.kr Received: July 22, 2017 / Accepted: August 23, 2017
This is an Open Access article distributed under the terms of the Creative Commons Attribution Non-Commercial License (http://creativecommons.org/licenses/by-nc/4.0/) which permits unrestricted non-commercial use, distribution, and reproduction in any medium, provided the original work is properly cited. 
that only $1.2 \%$ of the elderly, who responded in the survey, have participated in sports activities, $5.7 \%$ of whom participated in climbing and $17.8 \%$ of whom participated in walking. In consideration of the importance of the elderly people's participation in the exercises, the results show considerably low participation rates (Ministry of Health and Welfare, 2014).

The effects of the exercises performed by the elderly people are proven in all physical, psychological and social areas (Song et al., 1997). In order to encourage the elderly people to participate in exercises with such positive effects, it is urgently required to identify the motivation of the elderly on participating in the exercises voluntarily and determine the factors in continuous participation.

Motivation is the 'willingness to do something' and a motivation for participating in exercises not only offers a method to understand a person's behavior and decision, but also determines the direction, intensity, and persistence of the behavior. Based on the continuous participation in the exercises, including frequency, intensity, and duration, a person can participate in the exercises, and regularly perform the activities (Dishman, 1988).

Furthermore, the reason for continuing these exercises has to do with the feeling of euphoria, and there is a difference in the level of euphoria based on the exercise intensity, frequency, and duration (Lee, 2010). Euphoria refers to a positive, cognitive, and emotional state to which various factors are integrated, and it is experienced through physical activities, including leisure activities, rather than the satisfaction from the quality of life (Min and Kim, 2008). In other words, through exercise, people acquire positive thinking and attitude toward life, thereby resulting in feeling a psychological sense of happiness.

Therefore, the aim of the present study is to determine the effects of exercise motivation of the elderly people on euphoria.

\section{MATERIALS AND METHODS}

\section{Survey subjects}

The survey subjects in this study were 426 elderly people (over 65 years old) who are using the senior facilities (e.g., senior welfare centers, senior community centers, and neighborhood parks) located in Incheon.

\section{Survey tool}

\section{Configuration of the survey tool}

The questionnaire for the elderly people consisted of 9 questions on personal characteristics, 14 questions on exercise participation motives, and 21 questions on euphoria. The sports participation motives scale produced by Jeong (1997), which was a revision of the Sport Motivation Scale by Vallerand and Bissonnette (1992) and Pelletier et al. (1995), and the leisure intrinsic motivation by Weissinger and Bandalos (1995) were revised and supplemented to be used for the questionnaire for the motivation of participation in this study. The study also used the Korean Elderly People's Happiness Scale Questionnaire developed by Lim and Jeong (2009).

\section{Validity and reliability of the survey tool}

The verification of the questionnaire validity was performed with the confirmatory factor analysis (CFA) to examine the unidimensionality of the measured variables. In order to examine the fitness of each data, the study used $\chi^{2}, d f$, root-mean-square error of approximation (RMSEA), comparative fit index (CFI), TuckerLewis Index (TLI), average variance extracted (AVE), and concept confidence values. The validity of the fitness index of RMSEA $(\leq 0.08)$, CFI $(\geq 0.90)$, TLI $(\geq 0.90)$, AVE $(\geq 0.5)$, and concept confidence level $(\geq 0.7)$ were shown, thereby determining the validity of the survey tool used in the study. The results of the CFA are shown in Table 1.

The study analyzed the reliability with the items derived from the CFA by calculating Cronbach's a coefficient to verify the internal consistency among the items. The motivation for exercise participation was $0.702-0.899$ and euphoria was $0.814-0.889$, thereby showing that the reliability of the questionnaire was acquired.

\section{Data processing}

After excluding the data from the returned questionnaires, of which the responses were insufficient or unreliable, the other analyzable data were entered into the computer for analysis. According to the objectives of the study, the IBM SPSS ver. 18.0 (IBM Co., Armonk, NY, USA) and AMOS 18 (SPSS Inc., Chicago, IL, USA) were used. In order to determine the demographic attri-

Table 1. Confirmatory factor analysis results

\begin{tabular}{|c|c|c|c|c|c|c|c|c|}
\hline Scale & No. of questions & $\chi^{2}$ & $d f$ & TLI & $\mathrm{CFI}$ & RMSEA & AVE & $\mathrm{CR}$ \\
\hline Motivations for exercise participation & 14 & 695.415 & 325 & 0.906 & 0.918 & 0.054 & 0.561 & 0.789 \\
\hline Euphoria & 21 & 42.151 & 154 & 0.929 & 0.942 & 0.056 & 0.582 & 0.806 \\
\hline
\end{tabular}

$d f$, degrees of freedom; TLI, Tucker-Lewis Index; CFI, comparative fit index; RMSEA, root-mean-square error of approximation; AVE, average variance extracted; CR, composite reliability. 
butes, frequency analysis was performed, and to examine the validity of the questionnaire, the CFA was used. Cronbach's $\alpha$ was used for the reliability analysis, and a correlational analysis was performed in order to determine the correlation among the measured variables. In order to observe the difference between the level of exercise participation and euphoria of each elderly person, $F$-verification and postfactor verification were performed. Multiple regression analysis was used to investigate the effects of the motivations of exercise participation on psychological euphoria.

\section{RESULTS}

\section{The difference between exercise participation and euphoria of the elderly people}

In order to examine the difference between exercise participation and euphoria of the elderly people, the study analyzed the average, standard deviation, and $t$-validation. The results are shown below. There was a statistically significant difference in euphoria based on the exercise participation in all lower variables. In more detail, the group of elderly people, who participated in the exercises (mean: 3.78, 3.73, 2.51, 3.64, 4.36, 3.43), had a higher level of family relationship $(F=2.612)$, health $(F=7.837)$, work, and workplace $(F=3.152)$, psychological stability $(F=5.066)$, leisure $(F=17.472)$, and welfare $(F=9.280)$ than the group who did not perform exercises (mean: 3.56, 3.04, 2.19, 3.37, 3.40, 2.65). More detailed results are shown in Table 2.

\section{Correlation between the participation in exercises and euphoria of the elderly people}

In order to verify the degree of satisfaction with the validity of discrimination, a correlation analysis was performed. The results are shown in Table 3. Overall, the correlation coefficient among the factors was in the range of $0.000-0.717$. This was lower than 0.8 , which was the standard value of multicollinearity. Therefore, it is determined that issues surrounding multicollinearity can be disregarded (Kim, 2007).

\section{The effects of the exercise motivation for the elderly people on euphoria}

It was shown that the motivations for the participation in exercises, including fun, health, and relieving stress, had significant effects on family relationship, which is a low factor of euphoria. The result of verifying the determinant coefficient of the effect of the motivation for the participation in exercise on family relationship showed that $\mathrm{R}^{2}$ was 0.380 , thereby indicating that fun, health, and relieving stress would represent approximately $38 \%$ of family relationship.

It was shown that the motivations for the participation in exer-

Table 2. Difference in euphoria of the elderly people based on the participation in exercises

\begin{tabular}{lcccccc}
\hline Participation in exercises & Family relationship & Health & Work and workplace & Psychological stability & Leisure & Welfare \\
\hline Participation $(n=246)$ & $3.78 \pm 0.95$ & $3.73 \pm 0.91$ & $2.51 \pm 1.10$ & $3.64 \pm 0.49$ & $4.36 \pm 0.47$ & $3.43 \pm 0.93$ \\
Nonparticipation $(n=180)$ & $3.56 \pm 0.70$ & $3.04 \pm 0.88$ & $2.19 \pm 0.89$ & $3.37 \pm 0.60$ & $3.40 \pm 0.66$ & $2.65 \pm 0.72$ \\
$t$-value & $2.612^{* *}$ & $7.837^{* * *}$ & $3.152^{* * *}$ & $5.066^{* * *}$ & $17.472^{* * *}$ & $9.280^{* * *}$ \\
\hline
\end{tabular}

Values are presented as mean \pm standard deviation.

${ }^{* *} P<0.01 .{ }^{* *} P<0.001$.

Table 3. Correlation analysis and reliability analysis

\begin{tabular}{|c|c|c|c|c|c|c|c|c|c|c|}
\hline & 1 & 2 & 3 & 4 & 5 & 6 & 7 & 8 & 9 & 10 \\
\hline 1. Family relationship & 1 & & & & & & & & & \\
\hline 2. Health & $-0.083^{*}$ & 1 & & & & & & & & \\
\hline 3. Work and workplace & $0.279^{* *}$ & -0.036 & 1 & & & & & & & \\
\hline 4. Psychological stability & $0.425^{* *}$ & $-0.123^{* *}$ & 0.081 & 1 & & & & & & \\
\hline 5. Leisure & $0.321^{* *}$ & 0.041 & $0.133^{* *}$ & $0.115^{* *}$ & 1 & & & & & \\
\hline 6. Welfare & $0.150^{* *}$ & $0.103^{*}$ & $0.199 * *$ & $0.109^{* *}$ & $0.427^{* *}$ & 1 & & & & \\
\hline 7. Fun & $0.253^{* *}$ & $0.084^{*}$ & $0.101^{*}$ & $0.090^{*}$ & $0.606^{* *}$ & $0.450^{* *}$ & 1 & & & \\
\hline 8. Health & $-0.104^{*}$ & $-0.084^{*}$ & $-0.212^{* *}$ & 0.063 & 0.074 & 0.006 & -0.008 & 1 & & \\
\hline 9. Relieving stress & $-0.160^{* *}$ & $-0.134^{*}$ & $-0.167^{*}$ & -0.018 & -0.022 & -0.071 & -0.019 & 0.679 & 1 & \\
\hline 10. Social activities & $-0.107^{*}$ & $-0.144^{* *}$ & $-0.179 * *$ & 0.045 & 0.000 & -0.006 & 0.002 & 0.717 & 0.694 & 1 \\
\hline
\end{tabular}

${ }^{*} P<0.05 .{ }^{* *} P<0.01$, correlational coefficient is significant (both sides). 
cises, including fun, health, and relieving stress, had significant effects on health, which is a low factor of euphoria. The result of verifying the determinant coefficient of the effect of the motivation for the participation in exercise on health showed that $\mathrm{R}^{2}$ was 0.878 , thereby indicating that fun, health, and relieving stress would represent approximately $88 \%$ of health.

It was shown that the motivations for the participation in exercises, including fun and relieving stress, had significant effects on work and workplace, which is a low factor of euphoria. The result of verifying the determinant coefficient of the effect of the motivation for the participation in exercise on work and workplace showed that $\mathrm{R}^{2}$ was 0.875 , thereby indicating that fun and relieving stress would represent approximately $88 \%$ of work and workplace.

It was shown that the motivations for the participation in exer- cises, including fun and relieving stress, had significant effects on psychological stability, which is a low factor of euphoria. The result of verifying the determinant coefficient of the effect of the motivation for the participation in exercise on psychological stability showed that $\mathrm{R}^{2}$ was 0.397 , thereby indicating that fun and relieving stress would represent approximately $40 \%$ of psychological stability.

It was shown that the motivations for the participation in exercises, including fun, health, and relieving stress, had significant effects on leisure, which is a low factor of euphoria. The result of verifying the determinant coefficient of the effect of the motivation for the participation in exercise on leisure showed that $\mathrm{R}^{2}$ was 0.323 , thereby indicating that fun would represent approximately $32 \%$ of leisure.

Table 4. Regression analysis results of the elderly people's motivations of participation in exercises and euphoria

\begin{tabular}{|c|c|c|c|c|c|c|c|}
\hline Variable & B. & Standard error & $\beta$ & $t$ & $P$-value & F-value & $\mathrm{R}^{2}$ \\
\hline Family relationship & & & & & & 37.030 & 0.380 \\
\hline Fun & 0.328 & 0.115 & 0.183 & $2.848^{* *}$ & 0.005 & & \\
\hline Health & 0.368 & 0.071 & 0.387 & $5.183^{* * *}$ & 0.000 & & \\
\hline Relieving stress & 0.351 & 0.027 & 0.161 & $3.829 * * *$ & 0.000 & & \\
\hline Social activities & 0.040 & 0.021 & 0.086 & 1.929 & 0.054 & & \\
\hline Health & & & & & & 54.014 & 0.878 \\
\hline Fun & 0.128 & 0.063 & 0.106 & $2.024^{*}$ & 0.043 & & \\
\hline Health & 0.162 & 0.045 & 0.169 & $3.623^{* * *}$ & 0.000 & & \\
\hline Relieving stress & -0.265 & 0.080 & -0.209 & $-3.304^{* * *}$ & 0.001 & & \\
\hline Social activities & -0.047 & 0.053 & -0.047 & -0.879 & 0.380 & & \\
\hline Work and workplace & & & & & & 72.050 & 0.875 \\
\hline Fun & 0.394 & 0.076 & 0.265 & $5.171^{* * *}$ & 0.000 & & \\
\hline Health & -0.035 & 0.054 & -0.030 & -0.653 & 0.514 & & \\
\hline Relieving stress & 0.149 & 0.064 & 0.120 & $2.330^{*}$ & 0.020 & & \\
\hline Social activities & -0.044 & 0.097 & -0.028 & -0.452 & 0.652 & & \\
\hline Psychological stability & & & & & & 47.275 & 0.397 \\
\hline Fun & 0.394 & 0.076 & 0.265 & $5.171^{* * *}$ & 0.000 & & \\
\hline Health & -0.035 & 0.054 & -0.030 & -0.653 & 0.514 & & \\
\hline Relieving stress & 0.149 & 0.064 & 0.120 & $2.330^{*}$ & 0.020 & & \\
\hline Social activities & -0.044 & 0.097 & -0.028 & -0.452 & 0.652 & & \\
\hline Leisure & & & & & & 48.703 & 0.323 \\
\hline Fun & 0.207 & 0.030 & 0.314 & $6.915^{* * *}$ & 0.000 & & \\
\hline Health & 0.033 & 0.021 & 0.063 & 1.587 & 0.113 & & \\
\hline Relieving stress & 0.036 & 0.034 & 0.044 & 1.059 & 0.290 & & \\
\hline Social activities & -0.009 & 0.026 & -0.015 & -0.351 & 0.725 & & \\
\hline Welfare & & & & & & 45.008 & 0.374 \\
\hline Fun & 0.202 & 0.038 & 0.249 & $5.376^{* * *}$ & 0.000 & & \\
\hline Health & 0.065 & 0.026 & 0.100 & $2.472^{*}$ & 0.014 & & \\
\hline Relieving stress & 0.029 & 0.042 & 0.029 & 0.695 & 0.487 & & \\
\hline Social activities & -0.006 & 0.032 & -0.008 & -0.178 & 0.859 & & \\
\hline
\end{tabular}

${ }^{*} P<0.05$. ${ }^{* *} P<0.01 .{ }^{* *} P<0.001$. 
It was shown that the motivations for the participation in exercises, including fun and relieving stress, had significant effects on welfare, which is a low factor of euphoria. The result of verifying the determinant coefficient of the effect of the motivation for the participation in exercise on welfare showed that $\mathrm{R}^{2}$ was 0.374 , thereby indicating that fun and relieving stress would represent approximately $37 \%$ of work and workplace. More detailed results are shown in Table 4.

\section{DISCUSSION}

This study aimed at expanding the importance of the promotion of senior physical education and policy development from the perspectives of the elderly people's health promotion and reduction of medical expenses, as well as offering basic data that can contribute to the improvement of the quality of life and euphoria of the elderly people by determining the difference between their exercise participation level and euphoria, and the effects of exercise motivations on euphoria. In this section, the relationship among the variables derived from the analysis that was conducted above and the implications of the results are discussed.

First, the analysis results of the difference between the exercise participation and euphoria levels of the elderly people demonstrated that the group who participated in the exercises felt happier than the group who did not participate in the exercises. In more detail, it is believed that the elderly people who participated in the exercises had a higher level of euphoria than the group who did not participate in the exercises. Furthermore, the level of euphoria increased more with an increase in the participation level, thereby directly demonstrating the fact that participation in exercises would have a positive effect on solving various social and psychological issues that occur during old age. In particular, the effect of euphoria on overcoming various problems experienced by the elderly people (e.g., depression, alienation, despondency, helplessness, and psychological weakness) would be significant, and it is also effective in coping with stress.

Second, the analysis results on the effect of the elderly people's motivations for participating in exercises on euphoria showed that fun, which is a low variable of the exercise participation motivation, had a significant effect on euphoria in all low variables. It was also shown that health had a significant effect on family relationship, health, and welfare, while relieving stress had a significant effect on family relationship, health, workplace, and psychological stability variables. In more detail, the variable that had the biggest effect on euphoria as the elderly people participated in the exercises was the fun factor. Health and relieving stress were also considered to have a significant effect that were identical to the results of the elderly people's motivation for participating in the exercises. Furthermore, such results are partly supported by the results of the previous studies (Yoo et al., 2012), which reported that the motivation for exercise participation affects the psychological and subjective sense of happiness. While there should be various approaches to solving senior related issues in the aging society, various exercise programs focusing on the elderly people should be developed and distributed in line with the senior welfare policy, so as to improve their euphoria and quality of life. Moreover, the motivations for exercise participation should be considered in developing plans to encourage the elderly people to participate in the exercises.

In conclusion, the present study aimed to empirically determine the relationship between the degree of exercise participation by the elderly people and their euphoria. The analysis results are as follows.

First, the difference between the elderly people's participation in the exercises and the euphoria that they have experienced showed that in all low variables of euphoria, the group who participated in the exercises showed a higher level of euphoria than the group who did not participate in the exercises.

Second, the analysis of the effects of the elderly people's motivations for exercise participation on euphoria showed that there was a significant relation between the two. In particular, the fun factor among the low variables of participation motivations demonstrated the biggest effect on euphoria.

Furthermore, the following suggestions were made for areas that the current study did not cover, as well as for the follow-up studies. The follow-up studies would need an in-depth multiangled analysis of various fun factors in order to encourage the elderly people to participate in the exercises by conducting interviews and observation studies with the study participants.

\section{CONFLICT OF INTEREST}

No potential conflict of interest relevant to this article was reported.

\section{ACKNOWLEDGMENTS}

This work was supported by the National Research Foundation of Korea Grant funded by the Korean Government (NRF- 2012S1A5A2A03034025). 


\section{REFERENCES}

Dishman RK. Exercise adherence. Philadelphia (PA): Human Kinetics; 1988.

Jeong YG. The effect of the leisurely sports participants' sports participation motivations, arousal seeking, and emotion on sports absorption behavior [dissertation]. Busan (Korea): Pusan National University; 1997.

Kim GS. New AMOS 7.0 structural equation model analysis. Seoul: Hanarae; 2007.

Lee SD. Relationship among the fun factor, persistence in exercise, exercise addiction, and psychological sense of happiness in soccer participation. J Sport Leis Stud 2010;39:127-136.

Lim EG, Jeong TY. Searching for happiness factors of the Korean elderly people and the development of a happiness factor scale. J Korea Gerontol Soc 2009;29:1141-1158.

Min KH, Kim SK. The causal relationship between leisure activities and leisure satisfaction, and psychological well-being in professional soldiers. Korean J Leis Recreat Park 2008;32:21-32.

Ministry of Health and Welfare. Plan for ageing society and population: SAEROMAGI plan 2015 [Internet]. Sejong (Korea): Ministry of Health and Welfare; 2016 [cited 2017 May 1]. Available from: http://www.
mohw.go.kr/front_new/jb/sjb030301vw.jsp?PAR_MENU_ID=03\& MENU_ID=032901\&CONT_SEQ=336891\&page=1.

Ministry of Health and Welfare. Survey on the current conditions of elderly people. Seoul: The Korea Institute for Health and Social Affairs; 2014.

Pelletier LG, Tuson KM, Fortier MS, Vallerand RJ, Briere NM, Blais MR. Toward a new measure of intrinsic motivation, extrinsic motivation, and amotivation in sports: The Sport Motivation Scale (SMS). J Sport Exerc Psychol 1995;17:35-53.

Song R, Suh YO, Um YR, June KJ, Roberts BL. Effects of low-intensity exercise on functional ability in hospitalized elderly. J Nurs Acad Soc 1997;27:807-819.

Vallerand RJ, Bissonnette R. Intrinsic, extrinsic, and motivation styles as predictors of behavior: a prospective study. J Personal 1992;60:599620.

Weissinger E, Bandalos DL. Development, reliability, and validity of a scale to measure intrinsic motivation in leisure. J Leis Res 1995;27:379400.

Yoo CK, Seo SH, Lee BH. Relationship between participating motivation, sport commitment and the psychological happiness for golf participants. Korean J Sports Sci 2012;21:421-434. 